\title{
Küçük Ve Orta Büyüklükteki İşletmelerde Finansman Kaynağı Olarak COSME Programı: Örnek Uygulama*
}

\author{
Şule Yüksel YíĞiTER** \\ Hüseyin ÖZYí̆̈iT ***
}

\section{ÖZET}

Küçük ve orta büyüklükteki işletmelerin (KOBİ) ekonomik kalkınma açısından ülkemizde ve diğer ülkelerde üretim, yatırım ve istihdam faaliyetleri bakımından önemli bir yeri vardır. Bu bağlamda çalışmanın amacı Avrupa Birliği’ nin en güncel KOBİ finansman politikası olan Programme For The Competitiveness Of Enterprises And Small And Medium - Sized Enterprises (COSME) programının küçük ve orta büyüklükteki işletmeler açısından değerlendirilip hangi özelliklerinin kullanılacağını belirlemektir. Bu çalışmada; Erzincan ilinde faaliyetlerini sürdüren KOBI'ler arasından ticaret hacmi yüksek olan bir işletme seçilerek mali yapısı oran analizi ve karşılaştırmalı analiz yöntemi ile analiz edilmiştir. Analiz neticesinde işletmenin finansman sorunlarına COSME programı kapsamında; farklı pazarlarda ortak bulabilmesi, Avrupa Bölgesel Kalkınma Fonu ve Avrupa Sosyal Kalkınma Fonu gibi kuruluşlar vasıtasıyla yeni pazarlara ulaşması, farklı ürünler üretmeyi hedeflemesi doğrultusunda Büyüme Amaçlı Özkaynak Desteği projelerinden faydalanması gibi alternatif çözüm önerileri getirilmiştir. Bununla birlikte COSME programı ile finansman sağlamanın diğer finansman sağlama yöntemlerine göre (banka kredisi, diğer kişilere borçlanmak) daha az maliyetli ve daha faydalı olduğu öngörülmüş̧ür.

Anahtar Kelimeler: KOBİ, COSME Programı, Oran Analizi, Karşılaştırmalı Analiz.

JEL Sinıflandırması: G32, M21, O31.

\section{The COSME Program As A Resource Of Finance In Small And Medium-Sized} Enterprises: Sample Application

\section{ABSTRACT}

SMEs have an important place in terms of production, investment and employment activities in our country and other countries in terms of economic development. The aim of working in this context is to assess the characteristics of the COSME program, the most up-to-date SME financing policy of the European Union, in terms of small and medium-sized enterprises. In this study; Among the SMEs operating in Erzincan province, an enterprise with a high trade volume was selected and its financial structure was analyzed by the rate analysis and comparative analysis method. In the context of the COSME program for the financing problems of the operator as a result of the analysis; alternative solutions such as access to new markets through organizations such as European Regional Development Fund and European Social Development Fund and utilization of Growth-oriented Equity Support projects in order to target different products are introduced. Along with that providing financing with the COSME program is expected to be less costly and more useful than other forms of funding (bank loans, borrowing to other people).

Keywords: SME, Cosme Program, Rate Analysis, Comparative Analysis.

Jel Classification: G32, M21, O31.

\footnotetext{
* Bu çalışma “KOBİ’lerin Finansman Sorunlarına Avrupa Birliği KOBİ Finansman Politikalarıyla Çözüm Önerileri: Erzincan Uygulaması” isimli yüksek lisans tezinden türetilmiştir.

** Yrd. Doç. Dr. Şule Yüksel YİĞİTER, Erzincan Üniversitesi, İktisadi ve İdari Bilimler Fakültesi, İşletme Bölümü, syigiter@erzincan.edu.tr

*** Öğr. Gör. Hüseyin ÖZYİĞİT, Erzincan Üniversitesi, Kemah MYO, Finans-Bankacılık ve Sigortacılık

Programı, huseyinozyigit@erzincan.edu.tr
} 


\section{GİRiş}

KOBİ'ler ekonomik yapı açısından her ülkede önemli olarak görülmekte, iktisadi oluşumun temelini oluşturarak ülkelerin rekabet edilebilirliğinin temel taşını oluşturmaktadır (Demir vd., 2008: 5). Ayrıca KOBİ' ler günümüzde işsizliği önleyici, istidamı arttırıcı, bölgeler arası ekonomik farkı önleyici, büyük işletmeleri tamamlayıcı ve toplumsal politikaları belirleyenler için önemli bir rol üstlenmiştir (Giaoutzi vd., 1988: 2).

Dünya çapında ekonomik gelişim sürecinde söz sahibi olan devletler KOBİ' lerin önemini ve ekonomik büyümeye, istihdama, sosyal uyuma ve yerel gelişmeye katkılarını kabul etmektedir (OECD, 2000: 9). Gelirin ve ekonomik büyümenin düşük olduğu gelişmekte olan ekonomilerde küçük ve orta büyüklükteki işletmeler önemli bir rol oynamaktadır (Analaui ve Al-Madhoun, 2006: 1). Ekonomik faaliyetler için oldukça önemli olan KOBİ' ler birçok sorunun içinde faaliyetlerini sürdürmeye çalışmaktadır. Genel olarak bakıldığında en önemli sorunlardan birinin finansman sorunu olduğu sonucuna varılmaktadır (Arent vd., 2013: 108). KOBİ’ ler finansman sorununu çözmek isterken genellikle modern yöntemlerden ziyade banka kredileri veya yatırımcılara borçlanmak gibi klasik yöntemleri tercih etmektedirler (Demir ve Sütçü, 2002: 85).

Modern yöntemlere bakıldığında Avrupa Birliği KOBİ finansman politikaları çerçevesinde küçük ve orta büyüklükteki işletmelerin finansman politikalarıyla ilgili olarak; "Avrupa Birliği 2014 - 2020 Dönemi Horizon 2020", "COSME" ve "Entrepreneurship 2020 Action Plan" gibi güncel programlar kullanılmaktadır (www.kosgeb.gov.tr, 2017).

Çalışmanın amacı, küçük ve orta büyüklükteki işletmelerin mali yapılarının finansal analiz teknikleri yardımıyla incelenerek, finansman sorunlarına Avrupa Birliği KOBİ finansman politikalarından biri olan COSME Programı çerçevesinde farklı bir bakış açısı kazandırmak ve finansman sorunlarının çözümü için öneri getirmektir.

\section{COSME PROGRAMI (PROGRAMME FOR THE COMPETITIVENESS OF ENTERPRISES AND SMALL AND MEDIUUM - SİZED ENTERPRISES) ${ }^{1}$}

COSME Programı; 2.5 milyar Euro' luk bir bütçeyle, 2014 - 2020 yılları arasında faaliyet gösterecek olan işletmelerin ve KOBİ' lerin girişimciliğini ve rekabet edebilirliğini geliştirmek maksadıyla uygulanan bir Avrupa Birliği programıdır.

KOBİ ve girişimcilerin rekabet edebilmeleri amacına yönelik olarak oluşturulan COSME programı ile girişimcilerin rekabet edebilme güçlerinin artırılması hedeflenmektedir. Programın hedefleri, küçük ve orta büyüklükteki işletmelerin, mevcut ve potansiyel girişimcilerin finansa erişimine imkan vermek, pazarlara açılmasını kolaylaştırmak, işletmelere destek hizmetleri sunmak ve girişimciliği teşvik etmek olarak belirlenmiştir. Avrupa parlamentosu ve konseyi tarafindan uygulanan COSME programı tahminen 7 y1l için 2.3 milyar Euro bütçeyle 2014 yılında başlatılmış olup 2020 yılına kadar uygulanacaktır (www.kosgeb.gov.tr, 2017).

\footnotetext{
1"http://ec.europa.eu/enterprise/initiatives/cosme/index_en.htm”, 2015.
} 
Programın amaçları aşağıdaki gibidir:

- KOBİ'lerin finansa erişimini kolaylaştırmak,

- KOBİ'lerin kurulması ve büyümesi için elverişli ortamları yaratmak,

- Avrupa' da girişimsel kültürü teşvik etmek,

- Avrupa Birliği girişimcilerinin rekabet edebilirliklerini desteklemek, desteklemek

- KOBİ' lerin uluslararası hale gelmesini ve uluslararası pazarlara erişim imkanlarını

$\mathrm{Bu}$ hedefleri başarmak için COSME programı, girişimciliğin devamlılığını sağlamaktadır. Program başarılı bir şekilde sürdürülürken, KOBİ' lerin ve girişimcilerin programdan daha kolay faydalanmasına yönelik olarak, programda zaman zaman gerekli iyileştirmeler de yapılmaktadır.

COSME programı yenilikçi hedefler doğrultusunda gerçekleşen girişimleri desteklemek üzere oluşturulmuştur. Program özellikle uluslararası düzeyde, KOBİ ve girişimcilerin finansal sorunlarını çözümlemeyi amaçlamaktadır. Program sayesinde mevcut ve muhtemel sorunlar Avrupa Birliği düzeyinde daha etkili bir şekilde ele alınabilmektedir. Programın çözmeyi amaçladığı sorunlar:

- Pazarlardaki tekelcilik uygulamalarının önüne geçilmesi,

- Üye ülkelerde sürdürülen uygulamaların entegrasyonunu sağlamak,

- Avrupa Girişimci Fonu ve Avrupa Girişimci Ağı gibi kurumların hazırladığı raporların güvenilirliğini artırmak şeklinde sıralanmaktadır.

COSME programının temel niteliklerine bakıldığında, ulaşılmak istenilen sonuçlar aşağıdaki gibi ortaya konulmaktadır (http://ec.europa.eu, 2017):

- KOBİ lerin ve girişimcilerin finansal kaynaklara erişiminin daha kolay hale getirilmesi,

- Serbest meslek kollarının ve işletmelerin geliştirilmesi ile Avrupa Birliği ülkeleri düzeyinde iş olanakları yaratılması ve büyümede önemli bir kaynak oluşturulması,

- Üye devletlerin sürdürülebilir rekabet açısından durumunun iyileştirilmesi, girişimcilerin ve çalışan işgücü sayısının artırılması (işsizlik oranının azaltılması),

COSME programından kimlerin yararlanabileceği aşağıdaki gibi belirtilmiştir:

- Girişimciler (özellikle KOBİ' ler gerekli finansal kaynaklardan daha kolay yararlanabilecektir),

- Üye olmaya aday devletler, 
- Bayan girişimci adayları ve işletmelerinin kurulma aşamasında sıkıntılarla karşılaşan girişimciler,

- Üye devletler (politik reformların gerçekleştirilmesi ve sürdürülmesi noktasında)

\section{1. COSME Programının Yapısı ve Bileşenleri}

\section{1. 1. Finansmana Erişim}

Şirketler faaliyet dönemleri boyunca finansal desteklerden faydalanmaktadır. Finansal desteklerden en fazla faydalanılan dönem, genellikle işletmelerin kuruluş ve gelişme dönemleridir. COSME programı çerçevesinde, Büyüme Amaçlı Özkaynak Desteği (EFG), özellikle gelişme aşamasında işletmelere sermaye desteği sağlamaktadır. Kredi Garanti Desteği (LGF) programı ise, 150.000 Euro' a kadar olan borçları kapsamakta ve tüm KOBİ ler için uygulanmaktadır. Bu programlar Avrupa Yatırım Fonu tarafından yönetilmektedir.

\section{1. 2. Pazarlara Erişim Bileșeni}

Program kapsamında, girişimcilerin ve KOBİ' lerin uluslararası pazarlarda faaliyet göstermesi durumunda rehberlik ve danışmanlık hizmeti verilmektedir. Özellikle uluslararası pazarlarda tekelciliğin önlenmesi noktasında KOBI' ler desteklenmektedir. $\mathrm{Bu}$ sayede uluslararası pazarlarda rekabet edilebilirlik artarken, ortaklık kurmak teşvik edilmektedir.

\section{1. 3. Çerçeve Koşulların İyileştirilmesi Bileşeni}

Program KOBİ' lerin sürdürülebilirliği açısından çevre koşullarının iyileştirilmesini hedeflemektedir. $\mathrm{Bu}$ hedef doğrultusunda KOBİ' lerin üzerindeki idari ve düzenleyici iş yükünü azaltmaya yönelik çalışmalar yapılmaktadır. Program çerçevesinde;

- Avrupa Birliği yasalarının KOBİ' ler üzerinde etkisinin tespit edilmesi,

- KOBİ' ler için iş dostu yasalar geliştirilmesi,

- Ulusal ve bölgesel düzeyde faaliyet göstermek isteyen KOBİ' lerde "İlk Önce Küçük Düşün" prensibinin sağlamlaştırılması amaçlanmaktadır.

\section{1. 4. Girişimcilik Bileşeni}

Girişimciler ve KOBİ' ler iş hacminde büyüme ve sürdürülebilir rekabet açısından oldukça önemlidir. Bu nedenle girişimcilik başlığı COSME programının bileşenleri arasına alınmıştır. Program kapsamında Girişimcilik Eylem Planı 2020 ile girişimcilik kültürünün korunması ve girişimcilere eğitim verilmesi amaçlanmaktadır. Girişimcilik Eylem Planı 2020 ile özellikle genç ve kadın girişimcilere öncelik verilmektedir. 


\section{2. Finansmana Erişim Bileşenleri}

\subsubsection{Kredi Garanti Desteği (Loan Guarantee Facility) (LGF)}

Kredi Garanti Desteği (Loan Guarantee Facility) aracılı̆̆ıyla finansal aracılara (ör: garanti kuruluşları, bankalar, leasing firmaları vb), KOBİ' lere daha fazla kredi ve leasing desteği sağlanması amaçlanmaktadır. Riskin paylaşılmasıyla, COSME garantileri, geleneksel bankacılık sistemine erişimde zorluklar yaşayan birçok KOBI' nin kredi finansmanına erişimini kolaylaştırarak finansal aracıların finansman sağlayacakları KOBİ sayısını arttırmalarına katkı sağlayacaktır. (www.kosgep.gov.tr). COSME Kredi Garanti Desteği için 2014-2020 döneminde ayrılan toplam bütçe yaklaşık 740 milyon Euro’ dur. Avrupa Birliği üye ülkelerinde ve COSME ile ilgili ülkelerde kurulmuş ve faaliyet gösteren KOBI'ler COSME Kredi Garanti Desteğinden yararlanabilmektedir. Desteklenen KOBİ' ler etik prensiplere uygun olamayan faaliyetler yürütmemeli veya Avrupa Yatırım Fonu tarafından kısıtlanan bir veya daha fazla sektöre odaklanmamalıdır.

\subsubsection{Büyüme Amaçlı Özkaynak Desteği (Equity Facility for Growth) (EFG)}

Büyüme Amaçlı Özkaynak Desteği; programa dahil ülkelerdeki KOBİ’ lerin büyüme, araştırma ve inovasyon çalışmalarını erken evrelerden gelişim evrelerine kadar desteklemeyi amaçlamaktadır. COSME Programı altında Büyüme Amaçlı Özkaynak Desteği ile Avrupa Yatırım Fonu, seçilen fonlara yatırım yapmak suretiyle gelişme ve büyüme evresindeki KOBİ' lere risk sermayesi ve ara finansman desteği sunmaktadır. COSME Özkaynak Desteği için 2014-2020 döneminde ayrılan toplam bütçe yaklaşık 690 milyon Euro’ dur.

\section{UYGULAMA}

\section{1. Uygulamanın Amacı ve Önemi}

Uygulamanın; KOBİ' lerin finansal yapısını analiz etmesi, bu analiz neticesinde işletmeye var olan mali yapısı hakkında bilgi vermesi ve gelecek dönemlerde COSME programı ile finansman sağlama olanaklarından bahsetmesi bakımından; işletmenin verimliliğini artırmaya, sürekliliğini sağlamaya yönelik olarak yol gösterici olması ve iyi bir finansman politikasıyla güçlü bir mali yapıya sahip olmasına yardımcı olması açısından önem taşımaktadır.

\section{2. Uygulamanın Kapsamı ve Yöntemi}

COSME programının değerlendirilmesi amacıyla uygulama kapsamında örnek bir firma seçilmiştir. Firma, Erzincan ili sınırları içerisinde tekstil sektöründe faaliyet göstermektedir. Satılan ürünler yurtiçinden temin edilmektedir. Firmanın ürün yelpazesi kumaş, havlu, masa örtüsü, çarşaf vb. gibi ürünlerden oluşmaktadır. Firma, ürün satmanın yanı sıra kısmi ölçüde imalat da yapmaktadır. Perde, iş elbiseleri, bez çantalar vb. ürünleri üretmektedir.

Uygulamadaki veriler, firmaların muhasebe departmanından yüz yüze görüşme yöntemi ile sağlanmıştır. Firmadan sağlanan belgeler, bilanço ve gelir tablolarıdır. 2012, 2013 
ve 2014 yıllarına ait bu belgeler karşılaştırılıp daha sonra oran analizi ve karşılaştırmalı analiz yöntemiyle incelenip analiz edilmiştir.

Oran analizi; işletmenin finansal yapısı ve faaliyet yapısı sonuçlarını hem kendi içinde hem de sektör içindeki firmalarla karşılaştırmak amacıyla kullanılır (Çetiner, 2007: 92). Çalışmada yapılan analiz sonucunda ele alınan firmanın mali yapısını ortaya konarak fon ihtiyacının saptanması amaçlanmıştır. İşletmelerim temel kuruluş amacı, kar elde etmek ve faaliyetlerinde süreklilik sağlamaktır. İşletme bu amacını gerçekleştirmeye yönelik olarak, mali yapısını güçlendirmeyi ve en uygun finansman alternatiflerini belirlemeyi amaçlamaktadır (Chong, 2008: 26). Oran analizi, mali yapıyı tespit etmek ve alternatifleri değerleme açısından kullanılan faydalı yöntemlerden biridir (Erdoğan, 1997: 309).

Tablo 1. Oran Analizi Kapsamında Kullanılacak Oranlar

\begin{tabular}{|c|c|}
\hline Oran isimleri & Formül \\
\hline Net İşletme Sermayesi & Dönen Varlıklar - Kısa Vad. Yab. Kay. \\
\hline \multicolumn{2}{|l|}{ Likidite Oranları } \\
\hline Cari Oran & Dön Var. / Kisa Vad. Yab. Kay. \\
\hline Likidite (Asit-Test) Oranı & (Dön. Var. - Stoklar) / Kısa Vad. Yab. Kay. \\
\hline Nakit Oran & (Hazır Değ. + Menkul Kiy.) / Kisa Vad. Yab. Kay. \\
\hline \multicolumn{2}{|l|}{ Faaliyet Oranları } \\
\hline Alacak Devir Hızı & Net Satışlar / Ticari Alacaklar \\
\hline Alacak Tahsil Süresi (Gün) & 365/ Alacak Devir Hizı \\
\hline Stok Devir Hizı & Satışların Maliyeti/ Stoklar \\
\hline Stok Devir Süresi (Gün) & 365 / Stok Devir Hizı \\
\hline Aktif Devir Hızı & Net Satışlar / Aktif Toplamı \\
\hline \multicolumn{2}{|l|}{ Mali Yapı Oranları } \\
\hline Finansal Kaldıraç Oranı & Toplam Yab. Kay. / Aktif Toplamı \\
\hline Borçlanma Oranı & Toplam Yab. Kay. / Öz Kaynaklar \\
\hline \multicolumn{2}{|l|}{ Kısa Vad. Yab. Kay. / Aktif Toplamı } \\
\hline \multicolumn{2}{|l|}{ Kısa Vad. Yab. Kay./Toplam Yab. Kaynaklar } \\
\hline \multicolumn{2}{|l|}{ Kısa Vad. Yab. Kay. / Net Satışlar } \\
\hline \multicolumn{2}{|l|}{ Finansal Borçlar / Toplam Borçlar } \\
\hline Özkaynak Oranı & Özkaynak / Aktif Toplamı \\
\hline \multicolumn{2}{|l|}{ Duran Var. / Özkaynaklar } \\
\hline \multicolumn{2}{|l|}{$\begin{array}{l}\text { Duran Var./Devamlı Sermaye (Özkaynaklar + Uz. } \\
\text { Vad. Yab. Kay.) }\end{array}$} \\
\hline Faiz Karşılama Oranı & (Verg. Önc. Kar + Faiz Gid.) / Faiz Gid. \\
\hline \multicolumn{2}{|l|}{ Karlılık Oranları } \\
\hline Brüt Kar Marjı Oranı & Brüt Sat. Karı / Net Sat. \\
\hline
\end{tabular}




\begin{tabular}{|l|l|}
\hline Faaliyet Karı Marjı Oranı & Faaliyet Karı / Net Satışlar \\
\hline Net Kar Marjı Oranı & Dönem Net Karı / Net Satışlar \\
\hline Özkaynak Karlılık Oranı & Dönem Net Karı / Özkaynaklar \\
\hline Aktif Karlılık Oranı & Dönem Karı / Aktif Toplamı \\
\hline
\end{tabular}

\section{3. Firma Analizi}

Firma Analizi, bir firmanın durumunun ortaya konması amacı ile dört temel başlıkta yapılan inceleme ve araştırmalardır. Bu bağlamda piyasa analizi, teknik analiz, mali analiz ve yönetim analizi yapılarak firmanın önceki dönemlere ve faaliyet gösterdiği sektöre göre mevcut durumu ortaya konmaktadır (Akdoğan ve Tenker, 2005: 76).

Bu amaçla analizi yapılan firmanın; 2012, 2013 ve 2014 yıllarına ait karşılaştırmalı bilanço, karşılaştırmalı gelir tablosu, oran analizi sonuç tablosu, likidite oranları dağılımı tablosu, faaliyet oranları dağılımı tablosu, kaldıraç oranları dağılımı tablosu ve karlılık oranları dağılımı tablosu aşağıda gösterilmiştir.

Tablo 2. Firmanın Karşılaştırmalı Bilançosu

\begin{tabular}{|c|c|c|c|c|c|}
\hline \multicolumn{6}{|c|}{ DÜZELTİLMIŞ BİLANÇO ve GELİR TABLOSU } \\
\hline AKTİF & 31.12 .2014 & $\%$ & 31.12.2013 & $\%$ & 31.12.2012 \\
\hline I. Dönen Varlıklar & $568.454,79$ & 17 & $484.761,49$ & 9 & $441.419,01$ \\
\hline A. Hazır Değerler & 177.078,92 & 84 & 96.131,19 & 486 & $16.388,61$ \\
\hline 1. Kasa & $169.609,00$ & & $61.808,19$ & & $4.141,16$ \\
\hline 2. Bankalar & $1.389,26$ & & $4.166,82$ & & $12.247,45$ \\
\hline 3. Diğer Hazır Değerler & $6.080,66$ & & $30.156,18$ & & 0,00 \\
\hline B. Ticari Alacaklar & $9.000,98$ & 11 & 8.049,85 & -63 & $21.982,00$ \\
\hline 1. Alicilar & $9.000,98$ & & $8.049,85$ & & 0,00 \\
\hline 2. Verilen Depozito ve Teminatlar & 0,00 & & 0,00 & & $21.982,00$ \\
\hline C. Diğer Alacaklar & $4.429,43$ & 110 & 367,00 & -37 & 584,79 \\
\hline 1. Ortaklardan Alacaklar & $4.188,44$ & & 0,00 & & 0,00 \\
\hline 2. Diğer Çeşitli Alacaklar & 240,99 & & 367,00 & & 584,79 \\
\hline D. Stoklar & $363.144,78$ & 1 & $362.286,13$ & -4 & $380.397,81$ \\
\hline 1. Ticari Mallar & $363.144,78$ & & $362.286,13$ & & $380,397,81$ \\
\hline E. Diğer Dönen Varlıklar & $14.800,68$ & -17 & 17.927,32 & -18 & $22.065,80$ \\
\hline 1. Devreden Katma Değer Vergisi & $14.800,68$ & & $17.927,32$ & & $22.065,80$ \\
\hline II. Duran Varlıklar & $6.358,45$ & & $6.358,45$ & 145 & $2.585,21$ \\
\hline A. Maddi Duran Varlıklar & $5.968,45$ & & $5.968,45$ & 171 & $2.195,21$ \\
\hline 1. Demirbaşlar & $5.968,45$ & & $5.968,45$ & & $2.195,21$ \\
\hline
\end{tabular}




\begin{tabular}{|c|c|c|c|c|c|}
\hline B. Maddi Olmayan Duran Varlıklar & 390,00 & & 390,00 & & 390,00 \\
\hline 1. Kuruluş ve Örgütleme Giderleri & 390,00 & & 390,00 & & 390,00 \\
\hline AKTİF TOPLAMI & $574.813,24$ & 17 & 491.119,94 & 10 & $444.004,22$ \\
\hline
\end{tabular}

Bilanço kalemlerinin yüzdelik değişimleri hesaplanarak, işletmenin hazır değerleri 2012-2013 yıllarına nazaran 2013-2014 yıllarında daha az bir artış göstermiştir. Ticari ve diğer alacaklar 2013-2014 yıllarında yüksek seviyede artmıştır. Alacakların artma nedenlerinin araştırılması gerekmektedir. Satışlardaki artışla beraber artması firma açısından olumlu olurken, alacakların tahsil edilememesi nedeni ile artmasi olumsuz olarak yorumlanacak ve işletmeyi finansal açıdan zor duruma sokabilecektir. Stoklar 2013-2014 yıllarında artış göstermiştir. Stoklardaki artış da dikkatli bir şekilde izlenmeli, artış kapasite artışından ve satışlardaki artıştan kaynaklanmıyorsa önlem alınmalıdır. Maddi duran varlıklar 2012-2013 yıllarında artış gösterirken 2013-2014 yıllarında sabit kalmıştır. Maddi duran varlıkların 2013-2014 yıllarında sabit kalması, stoklardaki artışın kapasite artışından kaynaklanmadığının göstergesi olabilecektir. Maddi olmayan duran varlıklar 2012 - 2014 yılları arasında sabit kalmıştır.

\begin{tabular}{|c|c|c|c|c|c|}
\hline PASIF & 31.12 .2014 & $\%$ & 31.12 .2013 & $\%$ & 31.12 .2012 \\
\hline I. Kısa Vadeli Yabancı Kaynaklar & $526.504,29$ & 15 & 454.175,07 & 8 & $417.901,73$ \\
\hline A. Ticari Borçlar & $221.732,14$ & 48 & $149.443,14$ & 34 & $110.814,85$ \\
\hline 1. Satıcilar & $221.732,14$ & & $149.433,14$ & & $110.814,85$ \\
\hline B. Diğer Borçlar & $302.935,93$ & 1 & $302.835,93$ & -1 & $305.704,25$ \\
\hline 1. Ortaklara Borçlar & $302.550,61$ & & $302.450,61$ & & $305.318,93$ \\
\hline 2. Personele Borçlar & 385,32 & & 385,32 & & 385,32 \\
\hline $\begin{array}{cccc}\text { C. Ö̈denecek } & \text { Vergi } & \text { ve } & \text { Diğer } \\
\text { Yükümlülükler } & & & \end{array}$ & $1.836,22$ & -1 & $1.896,00$ & 148 & 764,62 \\
\hline 1. Ödenecek Vergi ve Fonlar & $1.467,67$ & & $1.564,01$ & & 468,36 \\
\hline 2. Ödenecek Sosyal Güvenlik Kesintileri & 368,55 & & 331,99 & & 296,26 \\
\hline D. Borç ve Gider Karşılıkları & $\mathbf{0 , 0 0}$ & & $\mathbf{0 , 0 0}$ & -100 & 618,01 \\
\hline $\begin{array}{l}\text { 1. Dönem Karı Vergi ve Diğer Yasal } \\
\text { Yükümlülük Karşılığı }\end{array}$ & $2.841,02$ & & $2.781,93$ & & $2.823,64$ \\
\hline $\begin{array}{l}\text { 2. Dönem Karının Peşin Ödenen Vergi ve } \\
\text { Diğ. Yük. Kar.(-) }\end{array}$ & $2.841,02$ & & $2.781,93$ & & $2.205,63$ \\
\hline II. Özkaynaklar & $48.308,95$ & 30 & $36.944,87$ & 41 & $26.102,49$ \\
\hline A. Ödenmiş Sermaye & $10.000,00$ & & $10.000,00$ & & $10.000,00$ \\
\hline 1. Sermaye & $10.000,00$ & & $10.000,00$ & & $10.000,00$ \\
\hline B. Geçmiş Yıllar Karları & $41.872,86$ & 34 & $31.030,48$ & 51 & $20.449,23$ \\
\hline 1. Geçmiş Yıllar Karları & $41.872,86$ & & $31.030,48$ & & $20.449,23$ \\
\hline C. Geçmiş Yıllar Zararları(-) & $14.927,99$ & & $14.927,99$ & & $14.927,99$ \\
\hline
\end{tabular}




\begin{tabular}{|c|l|l|l|l|l|}
\hline 1. Geçmiş Yıllar Zararları & $14.927,99$ & & $14.927,99$ & & $14.927,99$ \\
\hline D. Dönem Net Karı/Zararı & $\mathbf{1 1 . 3 6 4 , 0 8}$ & $\mathbf{4}$ & $\mathbf{1 0 . 8 4 2 , 3 8}$ & $\mathbf{2}$ & $\mathbf{1 0 . 5 8 1 , 2 5}$ \\
\hline 1. Dönem Net Karı & $11.364,08$ & & $10.842,38$ & & $10.581,25$ \\
\hline PASİF TOPLAMI & $\mathbf{5 7 4 . 8 1 3 , 2 4}$ & $\mathbf{1 7}$ & $\mathbf{4 9 1 . 1 1 9 , 9 4}$ & $\mathbf{1 0}$ & $\mathbf{4 4 4 . 0 0 4 , 2 2}$ \\
\hline
\end{tabular}

Ticari borçlar 2012 yılından 2014 yılına yüksek seviyede artış göstermiştir. Alacakların tahsil edilememesi ticari borçların artmasına sebep olabilir. Diğer borçlar neredeyse aynı seyirde devam etmiştir. 2014 yılında firmanın borç ve gider karşılığı yoktur. Özkaynaklar, geçmiş yıl karı ve dönem net karı 2012 - 2014 yılları arasında sürekli artmıştır.

Tablo 3. Firmanın Karşılaştırmalı Gelir Tablosu

\begin{tabular}{|c|c|c|c|c|c|}
\hline GELİR TABLOSU & 31.12 .2014 & $\%$ & 31.12 .2013 & $\%$ & 31.12 .2012 \\
\hline A. Brüt Satışlar & 291.616,48 & -4 & $305.242,96$ & 43 & 212.619,29 \\
\hline 1. Yurtiçi Satışlar & $291.616,48$ & & $305.242,96$ & & $212.619,29$ \\
\hline B. Net Satışlar & $291.616,48$ & -4 & $305.242,96$ & 43 & 212.619,29 \\
\hline C. Satışların Maliyeti(-) & $240.674,50$ & -3 & $248.460,93$ & 41 & $175.581,35$ \\
\hline 1. Satılan Ticari Mallar Maliyeti(-) & $240.674,50$ & & $248.460,93$ & & $175.581,35$ \\
\hline Brüt Satış Karı veya Zararı & $50.941,98$ & 10 & $56.782,03$ & 53 & $37.037,94$ \\
\hline D. Faaliyet Giderleri(-) & $35.734,58$ & -15 & $42.239,92$ & 78 & $23.633,05$ \\
\hline 1. Genel Yönetim Giderleri(-) & $35.734,58$ & & $42.222,97$ & & $23.633,05$ \\
\hline 2. Pazarlama Satış ve Dağıtım Giderleri(-) & 0,00 & & 16,95 & & 0,00 \\
\hline Faaliyet Karı veya Zararı & $15.207,40$ & 4 & 14.542,11 & 8 & $13.404,89$ \\
\hline E. Finansman Giderleri (-) & 967,30 & & $\mathbf{0 , 0 0}$ & & $\mathbf{0 , 0 0}$ \\
\hline 1. Kısa Vadeli Borçlanma Giderleri(-) & 967,30 & & 0,00 & & 0,00 \\
\hline $\begin{array}{l}\text { F. Diğer Faaliyetlerden Olağan Gider ve } \\
\text { Zararlar(-) }\end{array}$ & $\mathbf{0 , 0 0}$ & -100 & 917,80 & & $\mathbf{0 , 0 0}$ \\
\hline 1. Komisyon Giderleri(-) & $\mathbf{0 , 0 0}$ & -100 & 917,80 & & $\mathbf{0 , 0 0}$ \\
\hline Olağan Kar veya Zarar & $14.240,10$ & 4 & $13.624,31$ & 1 & $13.404,89$ \\
\hline G. Olağandıșı Gider ve Zararlar(-) & 35,00 & & $\mathbf{0 , 0 0}$ & & $\mathbf{0 , 0 0}$ \\
\hline 1. Diğer Olağandışı gider ve Zararlar(-) & 35,00 & & 0,00 & & 0,00 \\
\hline Dönem Karı veya Zararı & $14.205,10$ & 4 & $13.624,31$ & 1 & $13.404,89$ \\
\hline Dönem Net Karı veya Zararı & $14.205,10$ & 4 & $13.624,31$ & 1 & $13.404,89$ \\
\hline
\end{tabular}


Gelir tablosu kalemlerinin yüzdelik değişimleri hesaplanarak, firmanın satışları 20122013 yıllarında artarken 2013-2014 yıllarında azalma göstermiştir. Firma açısından bu durumun yorumlanabilmesi için sektörün satış rakamlarının da analiz edilmesi gerekir. Söz konusu azalış tüm sektörde mevcut ise, sadece firma için sıkıntılı bir durum olmayacaktır. Ancak satışlardaki azalış sadece incelenen firma için söz konusu ise önlem alınması gerekecektir. Satışların azalması işletmenin borç ödeme gücünü azaltmaktadır. Satışların maliyeti ve faaliyet giderleri 2013-2014 yıllarında azalmıştır. 2014 yılında ilk defa finansman gideri oluşmuştur. Dönem net karı 2012 - 2014 yılları arasında artış göstermiştir.

Tablo 4. Firmanın Oran Analizi Tablosu

\begin{tabular}{|l|l|l|l|}
\hline & 31.12 .2014 & 31.12 .2013 & 31.12 .2012 \\
\hline Net İşletme Sermayesi & 41.950 & 30.586 & 23.518 \\
\hline Cari Oran & 1,07 & 1,06 & 1,05 \\
\hline Likidite (Asit-Test) Oranı & 0,38 & 0,26 & 0,14 \\
\hline Nakit Oran & 0,33 & 0,21 & 0,03 \\
\hline Alacak Devir Hızı & 32,4 & 37,9 & 9,6 \\
\hline Alacak Tahsil Süresi (Gün) & 11 & 9 & 38 \\
\hline Stok Devir Hızı & 0,66 & 0,68 & 0,46 \\
\hline Stok Devir Süresi (Gün) & 553 & 536 & 793 \\
\hline Aktif Devir Hızı & 0,5 & 0,62 & 0,47 \\
\hline Finansal Kaldıraç Oranı & 0,91 & 0,92 & 0,94 \\
\hline Borçlanma Oranı & 10,8 & 12,2 & 16 \\
\hline Kısa Vad. Yab. Kay. / Aktif Toplamı & 0,91 & 0,92 & 0,94 \\
\hline Kısa Vad. Yab. Kay. / Toplam Yab. Kaynaklar & 1,00 & 1,00 & 1,00 \\
\hline Kısa Vad. Yab. Kay. / Net Satışlar & 1,8 & 1,48 & 1,96 \\
\hline Finansal Borçlar / Toplam Borçlar & 0,001 & 0,00 & 0,00 \\
\hline Özkaynak Oranı & 0,08 & 0,07 & 0,05 \\
\hline Duran Var. / Özkaynaklar & 0,13 & 0,17 & 0,09 \\
\hline $\begin{array}{l}\text { Duran Var. / Devamlı Sermaye(Özkaynaklar + Uz. Vad. } \\
\text { Yab. Kay.) }\end{array}$ & 0,13 & 0,17 & 0,09 \\
\hline Faiz Karşıma Oranı & 15,6 & 0,00 & 0,00 \\
\hline Brüt Kar Marjı Oranı & 0,17 & 0,18 & 0,17 \\
\hline Faaliyet Karı Marjı Oranı & 0,05 & 0,04 & 0,06 \\
\hline Net Kar Marjı Oranı & 0,04 & 0,04 & 0,06 \\
\hline Özkaynak Karlılı Oranı & 0,29 & 0,36 & 0,51 \\
\hline Aktif Karlılık Oranı & 0,02 & 0,02 & 0,03 \\
\hline & & & \\
\hline & & & \\
\hline
\end{tabular}


Grafik 1. 2012-2013-2014 Y1lları Likidite Oranları Dağılımı

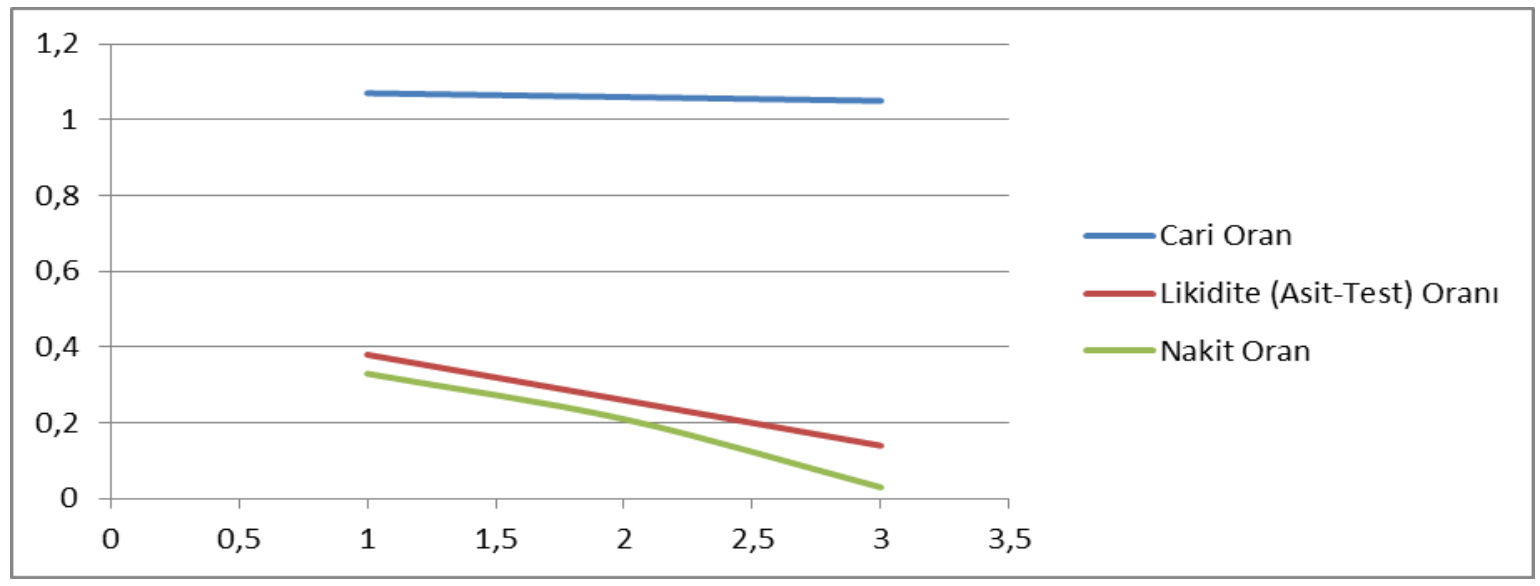

Grafik 2. 2012-2013-2014 Y1lları Kaldıraç Oranları Dağılımı

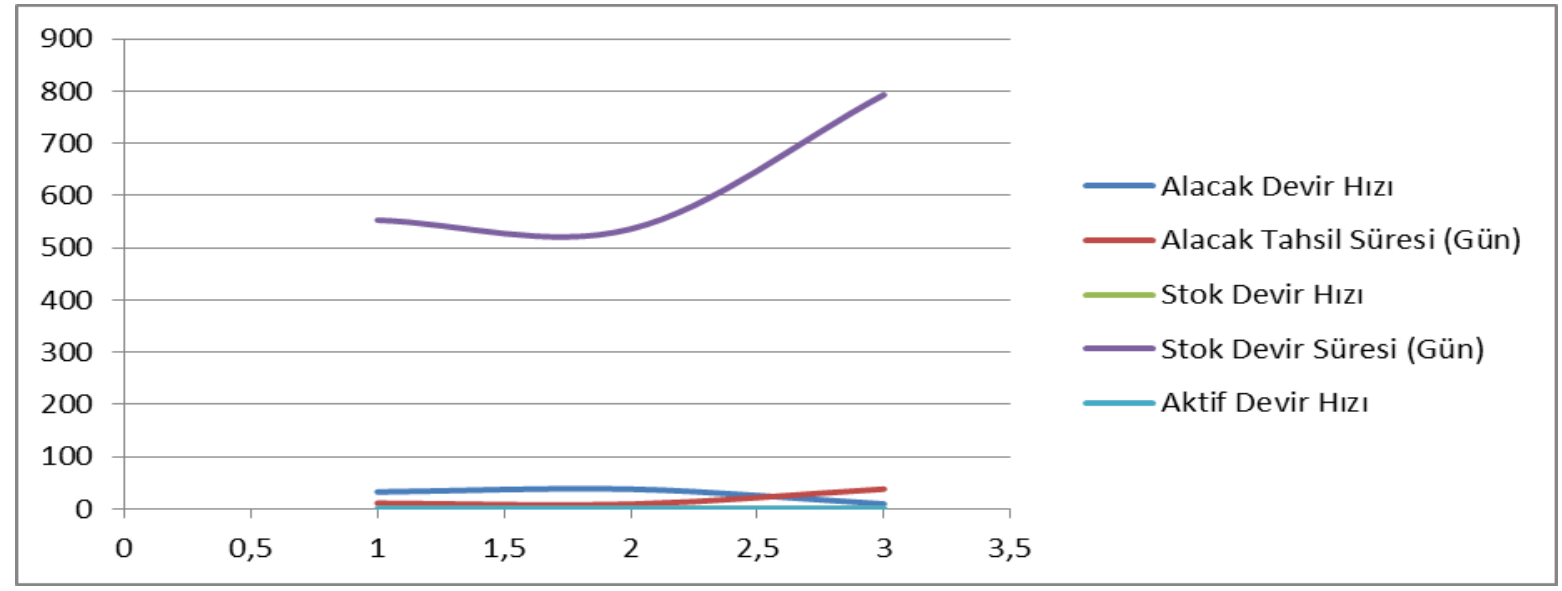

Grafik 3. 2012-2013-2014 Y1lları Faaliyet Oranları Dağılımı

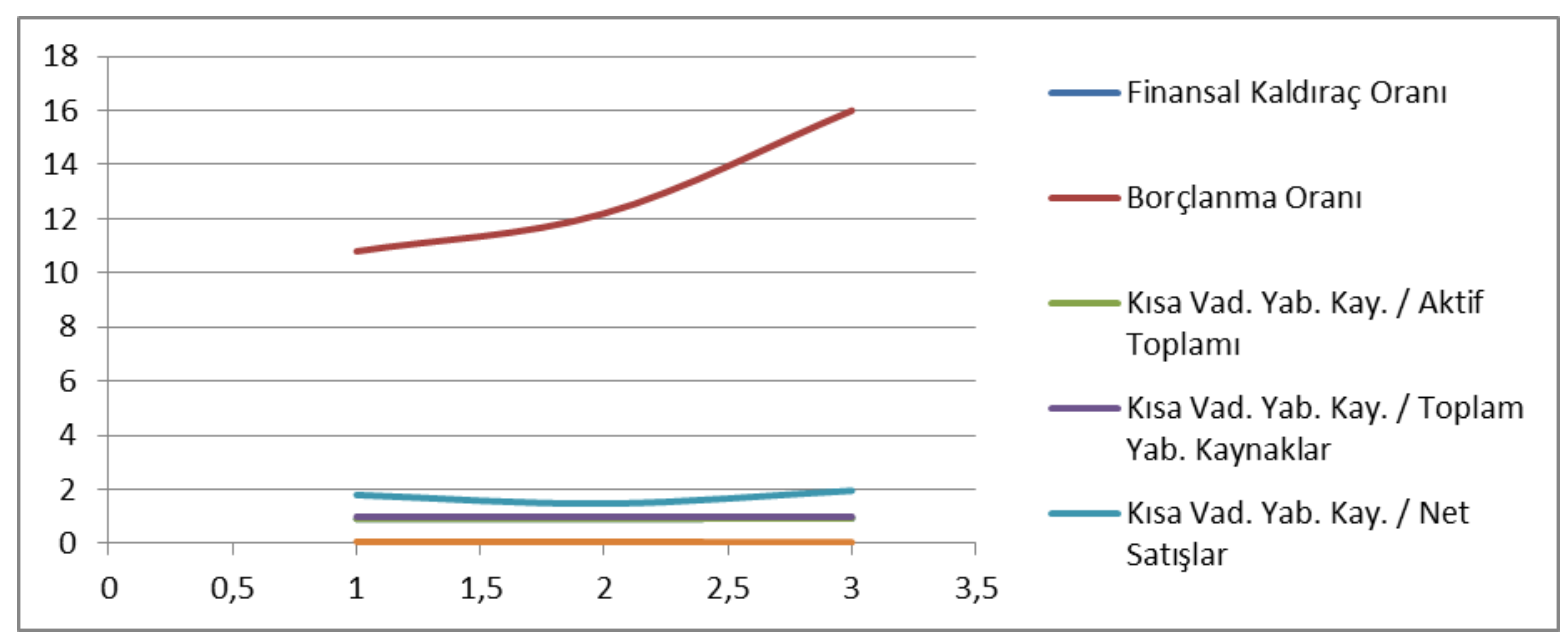


Grafik 4. 2012-2013-2014 Y1lları Karlılık Oranları Dağılımı

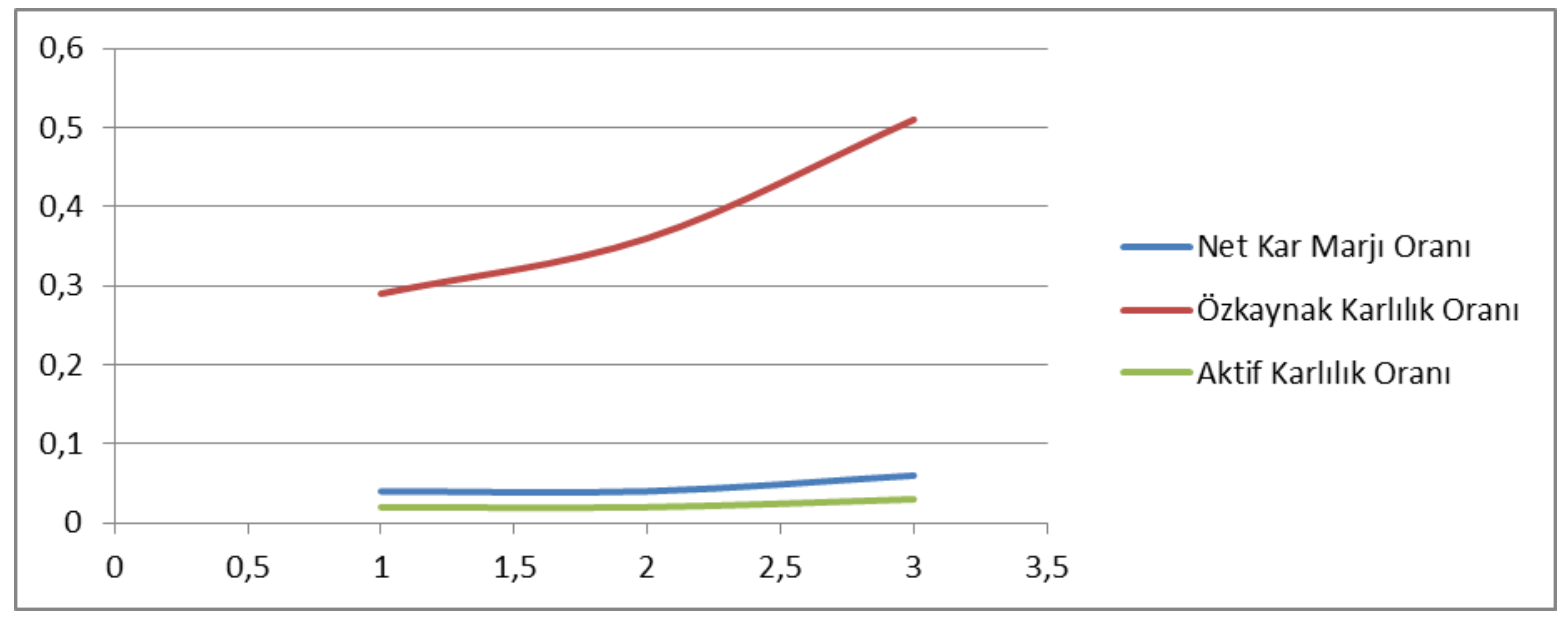

\section{4. Analiz Sonuç ve Önerileri}

Firmanın bilançosu incelendiğinde aktif toplamının yıllar itibariyle artış gösterdiği görülmektedir. $\mathrm{Bu}$ artışın kaynağı hem duran varlık kalemleri hem de dönen varlık kalemleridir. Hazır değerler başlı̆̆ incelendiğinde kasa hesabının dikkat çekici bir şekilde arttığı görülmektedir. $\mathrm{Bu}$ artışı en önemli nedenlerinde birisi işletmenin diğer hazır değerlerinin nakde çevrilmesi olarak yorumlanabilir. Ticari alacaklarda 2012-2013 yılları arasındaki azalışıı ve 2013-2014 yılları arasında meydana gelen artışın yorumlanabilmesi için satışlar kaleminin de incelenmesi gerekmektedir. Ticari alacaklar 2012-2013 yılları arasında azalırken net satı̧̧lar kalemi ilgili yıllar arasında artış göstermektedir. Bu durum satışların çoğunlukla peşin yapıldığının önemli bir göstergesi olabilmektedir. Ayrıca firmanın alacak tahsilatında sorun yaşamadığının işareti olarak yorumlanabilmektedir. Firma için olumlu yorumlara neden olan bu durumun 2013-2014 yılları arasında satışlar azalırken ticari alacakların artması ile bozulduğu görülmektedir. Çünkü satışlar azalırken ticari alacakların artması firmanın alacak tahsilatında sorunlar yaşadığının göstergesi olarak yorumlanmaktadır. Ticari alacaklar kalemi satışlarla ilişkili bir kalemdir. Müşteriye vade tanınması nedeniyle, satışlar artarken ticari alacakların artması olağan kabul edilmektedir. Bu doğrultuda satışlar azalırken ticari alacakların da azalması beklenir. Firmada satışlar azalırken ticari alacakların artması gittikçe artan şüpheli ticari alacak kaleminin varlığını ortaya koymaktadır. Alacak devir hızı ve alacak tahsil süresi oranları ticari alacak kaleminin yorumlanmasında dikkate alınması gereken iki önemli orandır. Alacakların 2013-2014 yılında satışların azalmasına rağmen artması olumsuz olsa da alacak devir hızı ve alacak devir süresinin artması aslında alacaklar açısından firmanın çok da kötü olmadığını göstermektedir. Bilançoda dikkati çeken bir başka hesap kalemi olan diğer alacaklar hesabının 2013-2014 yılları arasında ciddi bir artı̧̧ göstermesi ortaklardan alacaklar kaleminden kaynaklanmaktadır. Firmanın bilançosunda önemli olan bir diğer kalem stoklar kalemidir. Söz konusu kalemin, incelenen dönemler itibariyle önce küçük bir azalış daha sonrada kü̧̈ük artı̧̧ gösterdiği görülmektedir. Stoklar kalemi satışlarla doğrudan ilişkili bir kalem olduğundan her iki kalemin birlikte yorumlanması gerekmektedir. Stok kaleminin satışlar kalemi ile paralel şekilde artıp-azalması istenen bir durumdur. Aksi takdirde satışlar artarken stokların azalması talebin karşılanamama 
riskini doğururken, satışlar azalırken stokların artması stok maliyetlerinin (depolama, muhafaza etme, demode olma gibi) artması riskini ortaya çıkaracaktır. İncelenen firma açısından stoklar kalemi aktifin en yüksek tutardaki kalemidir. Bu durum ise stok kaleminin yönetimini daha da zorunlu kılmaktadır. Firma bu kaleme çok büyük miktarda fon bağlamıştır. Stok kalemin yorumlanabilmesi için, stok devir hızı ve stok devir süresinin de göz önünde bulundurulması gerekmektedir. Yapılan analiz sonucu incelendiğinde stok devir hızının düşük ve stok devir süresinin yüksek olduğu görülmektedir. Bu durum, stokların çok uzun süreler sonunda paraya çevrilebildiğini göstermesi bakımından firma açısından olumsuz yorumlanabilmektedir. 2012-2013 yılları arasındaki azalışın net satışların artması nedeniyle, 2013 - 2014 yılları arasındaki artışın ise yine net satışların azalması nedeniyle gerçekleştiği söylenebilir. Stoklar yüzdesel olarak küçük bir artış gösterse de bilançoda neredeyse en yüksek tutarlı kalemi oluşturmaktadır. $\mathrm{Bu}$ durumun çok iyi irdelenerek, fazla stok bulundurmanın nedenleri tespit edilmelidir. Nedenler sektör içinde analiz edilerek firma için en uygun stok düzeyinin belirlenmesi, stoklara bağlanan büyük miktarlardaki fonun daha etkin alanlarda kullanılmasına imkan verecektir. Böylece finansal açıdan bir rahatlama söz konusu olacağ 1 düşünülmektedir.

Analize tabi tutulan firmanın bilançosunun pasif tarafı incelendiğinde firmanın tamamen kısa vadeli yabancı kaynak kullandığı, uzun vadeli borçlanmaya gitmediği görülmektedir. Kısa vadeli borçlanmanın yıllar itibariyle artış göstermesi firmanın faaliyet gösterdiği pazarda saygın ve güvenilir kabul edildiği şeklinde yorumlanabilir. Çünkü satıcı kredilerinin varlığı ve yüksek olması piyasanın firmaya duyduğu güveni göstermektedir. Firmaların mali borçlanmadan ziyade ticari borçlanmaya başvurması finansman giderleri açısından olumlu kabul edilmektedir. Ancak firma bu seferde ödenen faizlerin vergi tasarrufu etkisinden faydalanamamaktadır. Bu nedenle, firmaların finansal kaldıracın olumlu çalıştığ seviyelerde yabancı kaynağa başvurmaları ödenecek vergi açısından firma lehine bir durum ortaya çıkaracaktır. Firma likiditesinin ve finansal yapısının yorumlanabilmesi için dikkate alınması gereken bir diğer önemli kalem net çalışma sermayesidir. Net çalışma sermayesi firmaların günlük faaliyetlerini yerine getirirken finansal açıdan sıkıntı çekip çekmediğini gösterir ve negatif olmaması istenir. Net çalışma sermayesinin negatif olması, dönen varlıkların kısa vadeli yabancı kaynakları karşılamaya yetmediğini gösterir ki, bu durum firmada finansal açıdan tehlike çanlarının çalmaya başladığı şeklinde yorumlanabilecektir. Ancak incelenen firmada, net çalışma sermayesinin pozitif olduğu ve net çalışma sermayesinin hesaplanmasında kullanılan her iki kaleminde aynı yönlü ve aynı düzeyde değişim gösterdiği görülmektedir. Bu nedenle firma açısında olumsuz olarak nitelendirilecek bir durum söz konusu değildir. Ayrıca firmada geçmiş yıllar karının etkisi ile öz kaynak kalemi artış eğilimi göstermektedir. Öz kaynak kalemi artış eğiliminde olmasına rağmen kaynak yapısı borç ağırlıklı oluşmaktadır. Buda kredi veren kuruluşlar açısından emniyet kar marjının çok düşük olduğunu ortaya koymaktadır ki firmanın finansal riskinin yüksek olduğu şeklinde yorumlara yol açmaktadır. Firma öz kaynaktan ziyade kısa vadeli yabancı kaynaklarla faaliyetini sürdürmektedir. $\mathrm{Bu}$ tablo da KOBI'lerin finansman desteğine ihtiyaçlarını daha net olarak göstermektedir.

Gelir tablosuna bakıldığında, işletmenin brüt satışları ve net satışlarının yıllar itibariyle önce ciddi bir artış daha sonra küçük bir düşüş gösterdiği görülmektedir. Satışların azalması sektördeki gelişmelerden kaynaklanan bir sorun olabileceği için sektör analizinin de yapılması gerekmektedir. Firma açısından incelenmesi gereken bir diğer kalemde satışların maliyeti 
kalemidir. Gelir tablosunda satışların maliyetinin önce ciddi bir oranda arttı̆̆ı daha sonra azalma eğiliminde olduğu görülmektedir. Satışların maliyeti kaleminin yüksekliği ya girdi maliyetlerinin yükselmesinden ya da verimliliğin düşmesinden kaynaklanıyor olabilir. $\mathrm{Bu}$ nedenle dikkatle incelenmesi gerekmektedir. Faaliyet giderleri 2012-2013 yılları arasında ciddi bir oranda artarken, 2013-2014 yılları arasında azalma eğilimine girmiştir. Faaliyet giderleri hesap grubu altında en önemli tutarı genel yönetim giderleri oluşturmaktadır. Pazarlama, satış ve dağıtım giderlerinin aksine genel yönetim giderleri satışlarla doğrudan ilişkili bir kalem değildir. Pazarlama, satış ve dağıtım giderleri satış artırmaya yönelik yapılan gider kalemleridir. Genel yönetim giderlerinin ise satışlar üzerinde doğrudan bir etkisi olmadığı kabul edilen gider kalemidir ve dikkatli bir şekilde gözden geçirilerek düşürülmesi yönünde önlemler gerekmektedir.

Net işletme sermayesi 2012 yılından 2014 yılına kadar artmıştır. İncelenen dönemlere bakıldığında 2014 yılında en yüksek değere sahip olduğu görülmektedir. Bu da işletmenin mali yapısının bozuk olmadığını, faaliyetlerini sürdürebilir olduğunu göstermektedir. Firmanın cari oranı 2012 yılından 2014 yılına kadar artmıştır, fakat 2012 ve 2014 yılları arasında istenilen değer olan 1,5' in altında kalmıştır. İşletmenin 2012, 2013 ve 2014 yıllarında likidite oranı sürekli artmıştır. İlgili yıllarda istenilen oran 1 değerinin altında kalmıştır. Cari ve likidite oranlarındaki değişimin firma açısından yorumlanabilmesi için sektör ortalamalarının göz önünde bulundurulması gerekmektedir. Ancak bu değişimin en önemli nedeni olarak kısa vadeli borçlanmanın artması gösterilebilir. Eğer firmadaki mevcut oranlar sektör ortalamasının altında ise ilerleyen süreçte kısa vadeli borçların ödenmesinde güçlükler yaşanabileceği sonucuna varılabilir. Söz konusu dönemlerde nakit oran1 2012 yılından itibaren yükselme eğilimine girmiştir. Bu yükselmenin nedeni firmanın diğer dönen varlıkları nakde çevirmesi olarak görülebilir. Ancak oranın tam olarak yorumlanabilmesi için sektör oranlarına bakılması faydalı olacaktır. Aktif devir hızı oranı incelendiğinde 2012' yılından 2013 yılına kadar bu oranın arttı̆̆ı, 2013' yılından 2014 yılına kadar ise düştüğü görülmektedir. Bu durum firmanın aktif varlıklarını etkin kullanamadığı şeklinde kanı oluşmasına neden olmaktadır. Firmanın finansal kaldıraç oranın oldukça yüksek olduğu görülmektedir. Bu oranın yüksek olması firmanın borç ödemelerinde sıkıntı yaşayabileceği ihtimalini ortaya çıkarmaktadır. Firmanın bilançosunun pasif tarafının borç lehine bozulması, söz konusu ihtimalin yaşanabileceği düşüncesini güçlendirmektedir. Yani firmanın borçlarını ödemede öz kaynaklarının yetersiz olduğu ve finansal riskinin yüksek olduğu söylenebilir. Firmanın bu durumda özkaynak yapısını güçlendirecek tedbirler alması tavsiye edilmektedir. Özkaynak oranı, 2012 yılından 2014 yılına kadar sürekli 0,50' nin altında kalmış ve çok az seviyede artmıştır. Türkiye gibi gelişmekte olan ülkelerde oranın 0,50' nin altında olması olağan kabul edilmesine rağmen söz konusu firmada bu oran oldukça düşüktür. Firma neredeyse 0,90 borç, 0,10 öz kaynakla finanse edilmektedir. Bu durumda firma yabancı kaynak sağlayıcılara bağımlı duruma gelebilecektir. Duran varlıklar özkaynaklara oranlandığında firmanın öz kaynaklarının duran varlık finansmanı için yeterli olduğu görülmektedir.

Yapılan bu analizler, firmanın sektör ortalamalarını da dikkate alarak özellikle likidite oranları ve kaldıraç oranlar noktasında iyileştirici tedbirler alması gerektiğini ortaya koymaktadır. Bu noktada Avrupa Birliği destek programları daha da önemli hale gelmektedir. 


\section{SONUÇ}

Türkiye' de ekonominin büyük çoğunluğunu KOBİ' ler oluşturmaktadır. KOBİ' lerin hem istihdam hem de üretim açısından bulunduğu bölge ve ülkeye önemli katkıları vardır. KOBI'ler ülkemizde istihdamın \% 52'sini, yatırımın \%7'sini, üretimin \% 38'ini ve ihracatın $\%$ 8' ini gerçekleştirmektedir. Bu oranların gelişmiş ülkelerde daha yüksek olduğu görülmektedir. Ekonomide çok önemli bir yeri olan KOBİ' lerin karşılaştıkları birçok sorun olmasına rağmen en önemli sorunlardan biri finansman sorunu olarak karşımıza çıkmaktadır. Finansman olanakları, KOBİ' lerin faaliyetlerini sürdürebilmeleri için önemli faktörlerden biri olarak kabul edilmektedir. Ülkemizde KOBİ lerin devlet kaynaklı olmayan finansman sağlama yolları kısıtlıdır. Genellikle devlet desteğinin olmadığı durumlarda, banka kredilerine veya özkaynak artırımı gibi klasik finansman yollarına başvurmaktadırlar.

Türkiye' de finansman sağlamada zorlanan KOBİ' lere önemli ölçüde destek ve hibe verilmektedir. Söz konusu desteklerin daha etkili olabilmesi yönünde hem ulusal hem de uluslararası düzeyde çalışmalar yapılmaktadır. Bu bağlamda Avrupa Birliği Kobi Politikaları ve Türkiye' deki KOBİ politikaları, KOBİ' lerin finansman sorunu başta olmak üzere mevcut sorunlarının çözümüne yönelik politikalar geliştirmeyi amaçlamaktadır. Avrupa Birliği KOBİ politikaları incelendiğinde en güncel programlardan birinin, COSME programı olduğu görülmektedir. Programda genellikle, iş kurmak için teşvik desteklerinin yer aldığ söylenebilir. Bununla beraber AR - GE, iş genişletme, üretim, çevre uyumu, teknoloji, sosyal ürünler, ürün geliştirme, eğitim, iş transferleri gibi birçok alanda destek verilmektedir. Özellikle bayan ve genç girişimciler için önemli derecede desteklerin var olması en dikkat çekici özelliktir. Ayrıca COSME programında "Web Tabanlı" ticaret için de eğitim ve destek hizmetleri yer almaktadır.

Avrupa Birliği' nin güncel politikaları 2020 yılını hedef almıştır. Bunun temel sebebi; sürekli iyileştirme, sürekli gelişme, doğru planlama, doğru yatırım, doğru finansman sağlama ve en yüksek verimi elde etmek için devamlılığın sağlanmasıdır. Politikalar çerçevesinde, ekonominin önemli bir bölümünü oluşturan KOBİ' lerin, en az maliyetli kaynağı kullanmasına yönelik en uygun alternatifler oluşturulmaya çalışılmaktadır. AB KOBİ politikaları, finansman desteğinin yanı sıra imalat üzerine de işletmeleri cesaretlendirmektedir. $\mathrm{Bu}$ da hem istihdam hem de finansman kaynağı olarak nitelendirilebilir. İşletmelerin maliyeti yüksek finansman kaynaklarına yönelmesi, işletmeyi iflasa kadar sürükleyebilecek bir süreçtir. İyi bir analiz yapılmaksızın verilen kararlar işletmeleri altından kalkamayacağ 1 ekonomik bir krize sürükleyebilmektedir. Genel olarak KOBİ' ler bulunduğu bölgeler için önem teşkil etmektedir. Asıl olan KOBI' lerin kurulması değil, kurulduktan sonra faaliyetine sağlıklı bir şekilde devam etmesidir. Avrupa Birliği KOBİ politikaları da bu bağlamda yürütülmektedir. Ayrıca COSME programı dahilinde girişimci ve KOBİ' lerin farkındalığını artırmaya yönelik eğitimler de verilmektedir.

Çalışmada KOBI' lerin finansman sorunlarına Türkiye'de KOSGEP tarafından koordinasyonu yürütülen COSME programı çerçevesinde çözüm aranmaya çalışılmıştır. Analiz edilen işletmenin COSME Programı kapsamında yer alan Kredi Garanti Desteğinden yararlanabileceği düşünülmektedir. Bu programdan faydalanabilmesi için program proje teklif çağrılarına başvurarak hem devlet hem de özel bankalar aracılığıyla finansman ve leasing desteği sağlayabilecektir. COSME Programı, finansman konularında finansal aracılar vasıtasıyla girişimcilere ve KOBİ'lere daha düşük maliyetlerle finansman kaynağı bulma 
imkanı sağlamaktadır. Ayrıca program işletmeler arası işbirliklerini de desteklediğinden, işletmenin farklı pazarlarda ortak bulabilmesi de mümkün görünmektedir. Firma COSME Programı paralelinde "2020 Girişimcilik Hareket Planı" çerçevesinde, Avrupa Bölgesel Kalkınma Fonu, Avrupa Sosyal Kalkınma Fonu gibi kuruluşlar vasıtasıyla yeni pazarlara ulaşma fırsatı yakalayabilecektir. Bunun yanı sıra işletme büyümeyi ve farklı ürünler üretmeyi hedefliyorsa Büyüme Amaçlı Özkaynak Desteği proje tekliflerini değerlendirebilecektir. Bu desteklerin yanı sıra COSME programı Girişimci Bileşeni doğrultusunda ev sahibi girişimcileri araştırma, geliştirme, yeni iş konseptleri geliştirme ve test etme, yeni girişimcilerin ürünler ve hizmetler hakkındaki yeni fikirlerini destekleme konularında teşvik etmekte ve eğitimler vermektedir. İşletmenin bu programlardan faydalanmasının da yararına olacağı düşünülmektedir.

\section{KAYNAKLAR}

Akdoğan, N. - Tenker, N. (2005), "Finansal Tablolar ve Mali Analiz Teknikleri”, 10. Bask1, Gazi Kitabevi, Ankara, 2005.

Analou1, Farhad - Al-madhoun, Mohammed (2006), "Empowering SME Managers in Palestine”, Ashgate Publishing, Ltd.

Arent, A. - Duarte, N. (2013), "The Role of SMEs in Sustainable Regional Development and Local Business Integration: The Case of Lublin Region” (Poland).

Chong, H. G. (2008), “Measuring Performance of Small-and-Medium Sized Enterprises: The Grounded Theory Approach”, Journal of Business and Public Affairs.

Çetiner, E. (2007), “İşletmelerde Mali Analiz”, Gazi Kitabevi, Ankara, 2007.

Demir, Yusuf - Sütçü, Abdullah (2002), “Kriz Sonrası Isparta Orman Endüstri KOBİ’lerinin Üretim, Teknoloji ve Finansman Sorunlarının Analizi”, Süleyman Demirel Üniversitesi Orman Fakültesi Dergisi.

Demir, Yusuf - Özdemir, Ozan - Eren, İsmail (2008); “Küçük ve Orta Ölçekli İşletmelerde Finansal Yönetim Uygulamaları", Asil Yayın Dağıtım, Ankara.

Erdoğan, N. (1997), “Mali Tablolar ve Analizi”, Ankara, Atilla Kitabevi.

Giaoutzı, Maria - Nijkamp, Peter - Storey, D. J. (1988), “Small and Medium Size Enterprises and Regional Development”, Routledge Publishing.

OECD (2000), “Enhancing SME Competitiveness”, The OECD Bologna Ministerial Conference.

http://ec.europa.eu/enterprise/initiatives/cosme/index_en.htm", (Çeviri), 01. 01. 2015.

http://ec.europa.eu/research/participants/data/ref/other_eu_prog/cosme/wp/cosme-wp2017_en.pdf, 20.09.2017.

www.kosgeb.gov.tr, 23.09.2017. 